\title{
Microscales of turbulence and heat transfer correlations
}

\author{
VEDAT S. ARPACI \\ Department of Mechanical Engineering and Applied Mechanics, University of Michigan, Ann Arbor, \\ MI 48109, U.S.A.
}

\begin{abstract}
The small-scale structure of forced, turbulent flows developed after Taylor and Kolmogorov is extended to that of buoyancy-driven flows. A thermal microscale

$$
\eta_{\theta} \sim\left(\frac{1+\operatorname{Pr}}{\operatorname{Pr}}\right)^{1 / 4}\left(\frac{v a^{2}}{\mathscr{P}_{\mathrm{B}}}\right)^{1 / 4}
$$

is proposed. Here $\operatorname{Pr}=v / a$ denotes the Prandtl number and $\mathscr{P}_{\mathrm{B}}$ the production of buoyant, turbulent cnergy. Threc limits of this scalc arc the Kolmogorov, Oboukhov-Corrsin and Batchclor scales, respectivcly. When expressed in terms of the buoyancy force rather than that of the buoyant production (energy), the proposed scale becomes
\end{abstract}

$$
\eta_{\theta} \sim\left(\frac{1+P r}{P r}\right)^{1 / 3}\left(\frac{v a}{g \beta \Delta T}\right)^{1 / 3}
$$

or, relative to a length scale $l$ characteristic for geometry

$$
\eta_{\theta} / l \sim \Pi_{\mathrm{N}}^{-1 / 3}
$$

where

$$
\Pi_{\mathrm{N}} \sim\left(\frac{P r}{1+P r}\right) R a
$$

is the fundamental dimensionless number for buoyancy-driven flows and $R a$ is the Rayleigh number. A heat transfer model based on this dimensionless number explains why the well-known correlation for natural convection,

$$
N u \sim R a^{n},
$$

leads to an exponent less than $1 / 3$ when it is considered for the buoyancy-driven flow between two horizontal plates.

\section{INTRODUCTION}

Following Taylor [1] and Kolmogorov [2], who respectively proposed an inviscid estimate for the dissipation in isothermal, turbulent flows and an isotropic estimate for the kinematic scales of this dissipation, the small-scale structure of turbulence has received increased attention. Kolmogorov's idea was extended to small scales of a dynamically passive scalar contaminant in turbulent flow, first by Oboukhov [3] and Corrsin [4] for small Prandtl fluids and later by Batchelor [5] for large Prandtl fluids. These scales have been used by Priestley [6] to model the turbulence in the lower atmosphere and by Townsend [7] to measure this turbulence, and by George and Capp [8] and Delichatsios [9] to model the buoyancy-driven, turbulent flow near a vertical plate.

Despite the intensive research on modeling and measurements on the small scales of turbulent flows, however, some fundamental aspects of these scales continue to remain untreated. For example:

1. The difference, if any, between the small scales of forced and buoyancy-driven flows.
2. The Prandtl number dependence of these scales for any Prandtl fluid.

3. The use of these scales in the correlation of heat transfer data.

The objective of this study is to treat these aspects of scales, and show also the relation between the small scales of turbulence and the scales of heat transfer. The study is divided into five sections. Following this introduction, Section 2 proposes a fundamental dimensionless number for natural convection ; Section 3 briefly reviews, in terms of this number, the heat transfer in laminar, natural convection near a wall; Section 4 originates, in terms of this number, a thermal microscale and employs it for the heat transfer in turbulent natural convection near a wall and Section 5 concludes the study.

\section{A DIMENSIONLESS NUMBER FOR NATURAL CONVECTION}

The well-known correlation for forced convection in incompressible and constant property fluids

$$
N u=f(\operatorname{Re}, \operatorname{Pr})
$$




\section{NOMENCLATURE}

$a$ thermal diffusivity, $k / \rho c$

$c$ specific heat

$F_{\mathrm{B}}$ buoyancy force

$F_{\mathrm{I}}$ inertial force

$F_{\mathrm{v}}$ viscous force

$g$ gravitational acceleration

$g_{1}$ gravitational acceleration vector

Gr Grashof number, $g \beta \Delta T l^{3} / v^{2}$

$k$ thermal conductivity

$K$ mean kinetic energy

$l$ a characteristic length for geometry

$n$ an exponent

$N u \quad$ Nusselt number, $h l / k$

Pr Prandtl number, $v / a$

$q$ heat flux

$Q_{\mathrm{H}}$ enthalpy flow

$Q_{\mathrm{K}}$ conduction heat flux

$R a$ Rayleigh number, $g \beta \Delta T l^{3} / v a$

Re Reynolds number, $\rho V l / \mu$

$s_{i j} \quad$ fluctuating rate of strain

$S_{i j} \quad$ mean rate of strain

$T$ temperature

$u$ root mean square of velocity fluctuation

$u_{i} \quad$ velocity fluctuation

$U_{i}$ mean velocity

$V \quad$ a characteristic velocity.

Greek symbols

$\beta \quad$ coefficient of thermal expansion

$\Gamma$ mean thermal transport $\delta \quad$ momentum boundary layer thickness

$\delta_{\theta} \quad$ thermal boundary layer thickness

$\Delta$ difference

$\varepsilon \quad$ viscous dissipation

$\varepsilon_{\theta} \quad$ thermal dissipation

$\eta \quad$ Kolmogorov scale.

$\eta_{\theta} \quad$ thermal microscale for $P r \geqslant 1$

$\eta_{\theta}^{*} \quad$ thermal microscale for $\operatorname{Pr} \leqslant 1$

$\theta$ temperature fluctuation

$\Theta$ mean temperature

$\Theta_{0}$ temperature of isothermal ambient

$\lambda$ Taylor scale

$\mu \quad$ dynamic viscosity

$v \quad$ kinematic viscosity

$\Pi_{N}$ dimensionless number for natural convection

$\rho$ density.

\section{Script symbols}

$\mathscr{D}_{j} \quad$ mean transport

$\mathscr{P}$ inertial production

$\mathscr{P}_{\text {B }} \quad$ buoyant production

$\mathscr{P}_{\theta}$ thermal production.

\section{Superscripts \\ $\sim$ instantaneous value \\ - mean value.}

shows the dependence of the Nusselt number $N u$ on the Reynolds number $R e$ and the Prandtl number $P r$. Also well known is the fact that $R e$ characterizes the momentum balance in forced flows, and $P r$ denotes the coupling, through enthalpy flow, of thermal balance to momentum balance. Following the arguments leading to equation (1), and replacing $R e$ with the Grashof number $G r$, earlier studies presumed

$$
N u=f(G r, P r)
$$

for natural convection. Equation (2) ignores the important fact that, unlike in forced convection, the momentum in natural convection is coupled, through buoyancy, to thermal energy. Including this fact, later studies on natural convection more appropriately assume, in terms of the Rayleigh number $R a$

$$
N u=f(R a, P r)
$$

for this convection. For the asymptotic cases of $\mathrm{Pr} \rightarrow$ $\infty$ and $\mathrm{Pr} \rightarrow 0$, equation (3) reduces to

$$
N u=f(R a), \quad \operatorname{Pr} \rightarrow \infty,
$$

and

$$
N u=f(\operatorname{RaPr}), \quad \operatorname{Pr} \rightarrow 0 .
$$

However, a dimensionless number involving both $R a$ and $P r$ for any Prandtl fluid and representing the heat transfer in natural convection more explicitly than cquation (3) has apparently remained neglected. The prime concern of this section is the development of this number which will prove essential for the description of laminar and turbulent natural convection.

Let the buoyancy-driven momentum balance be

$$
F_{\mathrm{B}} \sim F_{\mathrm{I}}+F_{\mathrm{V}}
$$

where $F_{\mathrm{B}}, F_{\mathrm{I}}$ and $F_{\mathrm{V}}$ denote respectively the buoyant, inertial and viscous forces. Also, let the thermal energy balance be

$$
Q_{\mathrm{H}} \sim Q_{\mathrm{K}}
$$

where $Q_{\mathrm{H}}$ and $Q_{\mathrm{K}}$ denote respectively the enthalpy flow and conduction. Then, from equation (6),

$$
\frac{F_{\mathrm{B}}}{F_{\mathrm{I}}+F_{\mathrm{V}}} \sim \frac{F_{\mathrm{B}} / F_{\mathrm{V}}}{\left(F_{\mathrm{I}} / F_{\mathrm{V}}\right)+1}
$$

and from equation (7)

$$
Q_{\mathrm{II}} / Q_{\mathrm{K}}
$$

Although the force ratios of equation (8) and the 
energy ratio of equation (9) are dimensionless, they depend on velocity which is a dependent variable in buoyancy driven flows. For example

$$
\frac{F_{\mathrm{B}}}{F_{\mathrm{v}}} \sim \frac{g(\Delta \rho) l^{2}}{\mu V}, \frac{F_{1}}{F_{\mathrm{v}}} \sim \frac{\rho V l}{\mu}, \frac{Q_{\mathrm{H}}}{Q_{\mathrm{K}}} \sim \frac{\rho c V l}{k},
$$

$l$ being a characteristic length, and the other notation being conventional. Now, combine equation (9) with equation (8) for a result independent of velocity. Thus

$$
\frac{\left(F_{\mathrm{B}} / F_{\mathrm{V}}\right)\left(Q_{\mathrm{H}} / Q_{\mathrm{K}}\right)}{\left(F_{\mathrm{l}} / F_{\mathrm{V}}\right)\left(Q_{\mathrm{K}} / Q_{\mathrm{H}}\right)+1} \sim \frac{R a}{P r^{-1}+1}
$$

or,

$$
\Pi_{\mathrm{N}} \sim\left(\frac{P r}{1+P r}\right) R a
$$

which is the appropriate dimensionless number for natural convection in any Prandtl fluid. Accordingly, a more explicit relation than equation (3) for heat transfer in natural convection is

$$
N u=f\left(\Pi_{\mathrm{N}}\right) .
$$

The limits of equation (11) corresponding to $\operatorname{Pr} \rightarrow \infty$ and $P r \rightarrow 0$, respectively, are equations (4) and (5), as expected.

Although the existence of $\Pi_{N}$ has never been directly shown, the integral solution given by Squire [10] almost five decades ago for the laminar, natural convection near a vertical plate leads to an expression in terms of $\Pi_{N}$. Since then the role of $\Pi_{N}$ in studies on natural convection appears to be neglected.

Because of its importance to the present study, Squire's work is briefly reviewed here following the dimensional arguments of Rukenstein [11] and Arpaci and Larsen [12]. Let the momentum balance be

$$
u \frac{u}{l}+v \frac{u}{\delta^{2}} \sim g \beta \Delta T
$$

$\delta$ being the thickness of the momentum boundary layer, $l$ a length characterizing the geometry. Also, let the thermal energy balance be

$$
u \frac{\theta}{l} \sim a \frac{\theta}{\delta_{\theta}^{2}}
$$

$\delta_{\theta}$ being the thickness of the thermal boundary layer. Now, solve equation (13) for velocity,

$$
u \sim a \frac{l}{\delta_{\theta}^{2}}
$$

Insert equation (14) into equation (12), neglect by following Squire the shear stress at $\delta_{\theta}$ relative to that at the boundary (Fig. 1), and assume

$$
\delta \sim \delta_{\theta} .
$$

Thus, from equations (12), (13) and (14),

$$
\frac{l}{\delta_{\theta}^{4}}\left(1+\frac{a}{v}\right) \sim \frac{g \beta \Delta T}{v a}
$$

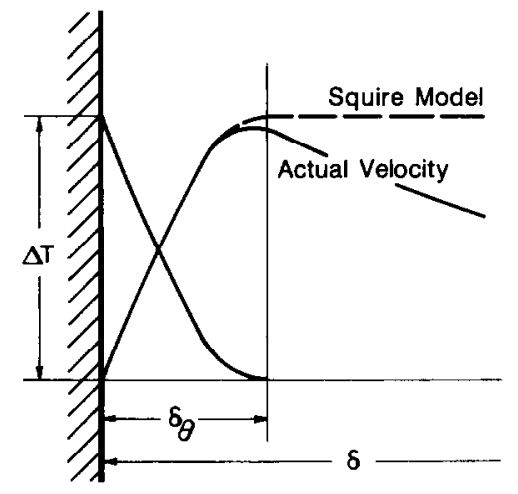

FIG. 1. Squire model for velocity of natural convection.

or, in terms of $\Pi_{N}$,

$$
\frac{l}{\delta_{\theta}} \sim \Pi_{N}^{1 / 4} \sim N u
$$

The next section is devoted to a thermal microscale in terms of $\Pi_{\mathrm{N}}$.

\section{A THERMAL MICROSCALE}

Following the usual practice, decompose the instantaneous velocity and temperature of a buoyancydriven, turbulent flow into a temporal mean (denoted by capital letters) and fluctuations

$$
\tilde{u}_{i}=U_{i}+u_{i} \text { and } \tilde{\theta}=\Theta+\theta,
$$

and let $U_{1}$ and $\Theta$ be statistically steady.

For this flow, the balance of the mean kinetic energy of velocity fluctuations yiclds (sec, for example. Tennekes and Lumley [13])

$$
U_{j} \frac{\partial K}{\partial x_{j}}=-\frac{\partial \mathscr{Q}_{j}}{\partial x_{j}}+\mathscr{P}_{\mathrm{B}}+\mathscr{P}-\varepsilon
$$

where

$$
K=\frac{1}{2} \overline{u_{i} u_{i}}
$$

is the mean kinetic energy,

$$
\mathscr{D}_{j}=\frac{1}{2} \overline{p u_{j}}+\frac{1}{2} \overline{u_{i} u_{i} u_{j}}-2 v \overline{u_{i} s_{u j}}
$$

is the mean transport (turbulent flux),

$$
\mathscr{P}_{\mathrm{B}}=-g_{j} \overline{u_{j} \theta} / \Theta_{0}
$$

is the buoyant production,

$$
\mathscr{P}=-\overline{u, u} S_{i j}
$$

is the inertial production, and

$$
\varepsilon=2 v \overline{s_{i j} s_{i j}}
$$

is the dissipation of turbulent energy. Here $g_{j}$ denotes the vector acceleration of gravity and $\Theta_{0}$ a characteristic mean temperature to be explained later.

Also, the balance of the root mean square of tem- 
perature fluctuations results in

$$
U_{j} \frac{\partial}{\partial x_{j}}\left(\frac{1}{2} \overline{\theta^{2}}\right)=-\frac{\partial \Gamma}{\partial x_{j}}+\mathscr{P}_{\theta}-\varepsilon_{\theta},
$$

where

$$
\Gamma_{j}=\frac{1}{2} \overline{\theta^{2} u_{j}}-a \frac{\partial}{\partial x_{j}}\left(\frac{1}{2} \overline{\theta^{2}}\right)
$$

is the mean thermal transport (turbulent thermal flux)

$$
\mathscr{P}_{\theta}=-\bar{u} \theta \frac{\partial \Theta}{\partial x_{j}}
$$

is the thermal production, and

$$
\varepsilon_{\theta}=a \frac{\overline{\partial \theta}}{\partial x_{j}} \frac{\partial \theta}{\partial x_{j}}
$$

is the thermal dissipation.

For a homogeneous pure shear flow (in which all averaged quantities except $U_{i}$ and $\Theta$ are independent of position and in which $S_{i j}$ is a constant), equations (17) and (18) reduce to

$$
\left(-\mathscr{P}_{\mathrm{B}}\right)=\mathscr{P}+(-\varepsilon)
$$

and

$$
\mathscr{P}_{\theta}=\varepsilon_{\theta} .
$$

Equation (19) states that a part of the buoyant production is converted into inertial production while the rest of it is dissipated.

Under isotropy, equations (19) and (20) lead, on dimensional grounds, to

$$
\mathscr{P}_{\mathrm{B}} \sim \frac{u^{3}}{\eta}+v \frac{u^{2}}{\eta^{2}}
$$

and

$$
u \frac{\theta^{2}}{\eta_{\theta}} \sim a \frac{\theta^{2}}{\eta_{\theta}^{2}}
$$

where $\eta$ is the Kolmogorov scale and $\eta_{\theta}$ is a thermal microscale. A buoyancy-driven flow, say, the natural convection above a heated, horizontal plate is unstable except for a thin, viscous layer next to the plate (the Rayleigh-Taylor instability). Under turbulent conditions, the thickness of this layer may be assumed to be $\eta$. In terms of the simple intuitive models developed by Corrsin [14] and Tennekes [15], this dissipation may be estimated as $v\left(u^{2} / \eta^{2}\right)$ (Fig. 2). Similarly, the thermal dissipation is to be estimated as $a\left(\theta^{2} / \eta_{\theta}^{2}\right)$.

Now, following Squire's postulate for heat transfer in buoyancy-driven, laminar flow [equation (15) and Fig. 1], assume

$$
\eta \sim \eta_{\theta}
$$

That is, the appropriate length scale for equation (21) is $\eta_{\theta}$ when this equation is to be considered for heat transfer. Hereafter, equation (23) is assumed to characterize a buoyant sublayer. Accordingly, letting

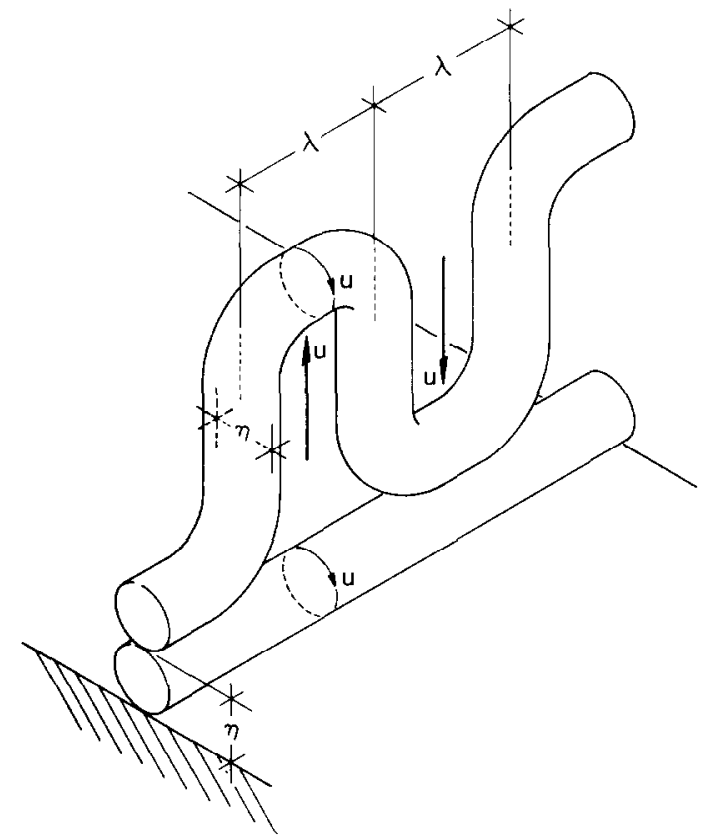

Fig. 2. Stable and unstable Tennekes vortex.

$\eta \rightarrow \eta_{\theta}$ in equation (21) and inserting $u$ obtained from equation (22) into this result yields for any Prandt] fluid

$$
\eta_{\theta} \sim\left(\frac{1+P r}{P r}\right)^{1 / 4}\left(\frac{v a^{2}}{\mathscr{P}_{\mathrm{B}}}\right)^{1 / 4},
$$

or, alternatively,

$$
\eta_{\theta}^{*} \sim(1+\operatorname{Pr})^{1 / 4}\left(\frac{a^{3}}{\mathscr{P}_{\mathrm{B}}}\right)^{1 / 4}
$$

$\eta_{\theta}$ being convenient for fluids with $\operatorname{Pr} \geqslant 1$ and $\eta_{\theta}^{*}$ for fluids with $\operatorname{Pr} \leqslant 1$.

Now, it is a simple matter to show that

$$
\lim _{P r \rightarrow \infty} \eta_{\theta} \rightarrow\left(\frac{v a^{2}}{\mathscr{P}_{\mathrm{B}}}\right)^{1 / 4}
$$

and

$$
\lim _{P r \rightarrow \infty} \mathscr{P} \rightarrow 0
$$

which implies, in view of equation (19),

$$
\mathscr{P}_{\mathrm{B}} \rightarrow \varepsilon .
$$

Then, from equations (26) and (28),

$$
\lim _{P r \rightarrow \infty} \eta_{\theta} \rightarrow \eta_{\theta}^{\mathbf{B}} \sim\left(\frac{v a^{2}}{\varepsilon}\right)^{1 / 4}
$$

which is the scale previously introduced by Batchelor [5]. Also

$$
\lim _{P r \rightarrow 0} \eta_{\theta}^{*} \rightarrow\left(\frac{a^{3}}{\mathscr{P}_{\mathrm{B}}}\right)^{1 / 4}
$$


and

$$
\lim _{P r \rightarrow 0} \varepsilon \rightarrow 0
$$

which implies, in view of equation (19),

$$
\mathscr{P}_{\mathrm{B}} \rightarrow \mathscr{P}
$$

and in a viscous layer much thinner than $\eta_{\theta}$

$$
\mathscr{P} \sim \varepsilon .
$$

From equations (30), (31) and (32)

$$
\lim _{P r \rightarrow 0} \eta_{\theta}^{*} \rightarrow \eta_{\theta}^{c} \sim\left(\frac{a^{3}}{\varepsilon}\right)^{1 / 4}
$$

which is the scale introduced by Oboukhov (3) and, independently, by Corrsin [4]. Finally, when $\operatorname{Pr} \sim 1$, because of the equipartition of buoyant production into inertial production and viscous dissipation, equation (19) becomes

$$
\mathscr{P}_{\mathrm{B}} \sim 2 \varepsilon
$$

and

$$
\lim _{P_{r \rightarrow 1}} \eta_{\theta}, \eta_{\theta}^{*} \rightarrow \eta \sim\left(\frac{v^{3}}{\varepsilon}\right)^{1 / 4}
$$

which is the celebrated Kolmogorov scale [2].

To date the relation between the small scales of turbulence and the scales used in the correlation of natural and forced convection data appears to remain unnoticed. To demonstrate this relation, return to the small scale proposed for buoyancy-driven flows,

$$
\eta_{\theta} \sim\left(\frac{1+P r}{P r}\right)^{1 / 4}\left(\frac{v a^{2}}{\mathscr{P}_{\mathrm{B}}}\right)^{1 / 4}
$$

and assume, on dimensional grounds,

$$
\mathscr{P}_{\mathrm{B}} \sim g u \theta / \Theta_{0} .
$$

Let $\Theta_{0}$ be the temperature of the isothermal ambient. Noting

$$
\Theta_{0}^{-1}=\beta
$$

$\beta$ being the coefficient of thermal expansion, rearrange equation (34) as

$$
\mathscr{P}_{\mathbf{B}} \sim g u \beta \theta
$$

or, with the velocity obtained from equation (22),

$$
u \sim a / \eta_{\theta}
$$

as

$$
\mathscr{P}_{\mathbf{B}} \sim g a \beta \theta / \eta_{\theta} .
$$

Insertion of equation (37) into equation (24) yields, after some rearrangement,

$$
\eta_{\theta} \sim\left(\frac{1+P r}{P r}\right)^{1 / 3}\left(\frac{v a}{g \beta \theta}\right)^{1 / 3} .
$$

Further, assuming the buoyant sublayer to control heat transfer, let

$$
\theta \sim \Delta T
$$

$\Delta T$ being the imposed temperature difference between the wall and ambient. Thus, equation (38) becomes, in terms of equation (39),

$$
\eta_{\theta} \sim\left(\frac{1+P r}{P r}\right)^{1 / 3}\left(\frac{v a}{g \beta \Delta T}\right)^{1 / 3 .}
$$

or, in terms of a characteristic scale for geometry, $l$,

$$
\frac{\eta_{\theta}}{l} \sim\left(\frac{1+P r}{P r}\right)^{1 / 3} R a^{-1 / 3} \sim \Pi_{\mathrm{N}}^{-1 / 3}
$$

where

$$
R a=\frac{g \beta \Delta T l^{3}}{v a}
$$

is the Rayleigh number.

In summary, the small (or micro) scales of turbulence are also the scales characterizing the heat transfer in buoyancy driven flows. The apparent difference in these scales, as demonstrated by the thermal scale proposed in this section, comes from the fact that the turbulence scale given by equation (24) is in terms of the buoyant (production of) energy while the equivalent heat transfer scale given by equation (40) is in terms of buoyancy (force). The next section is devoted to a heat transfer model for buoyancy-driven flows to be based on the proposed scale.

\section{HEAT TRANSFER}

With the definition of heat transfer coefficient $h$, and that of Nusselt number $\mathrm{Nu}$,

$$
N u=\frac{q_{\text {conv }}}{q_{\text {cond }}}=\frac{\left(q_{\text {cond }}\right)_{\text {wall }}}{q_{\text {cond }}}
$$

and with the assumption that near a wall the conduction in buoyancy-driven, turbulent flows is characterized by thickness of the buoyant sublayer,

$$
N u=\frac{h l}{k} \sim \frac{k\left(\Delta T / \eta_{\theta}\right)}{k(\Delta T / l)} \sim \frac{l}{\eta_{\theta}}
$$

where $k$ is the thermal conductivity of the buoyant fluid.

Now, combining equation (42) with cquation (41), and assuming the heat transfer in buoyancy-driven, turbulent flow to be controlled by the buoyant sublayer

$$
N u \sim \Pi_{N}^{1 / 3} .
$$

The limits of equation (44) for $\operatorname{Pr} \rightarrow 0, \operatorname{Pr} \rightarrow 1$ and $\operatorname{Pr} \rightarrow \infty$

$$
\begin{aligned}
& \lim _{P r \rightarrow 0} N u \sim(R a P r)^{1 / 3} \\
& \lim _{P r \rightarrow 1} N u \sim G r^{1 / 3} \\
& \lim _{P r \rightarrow \infty} N u \sim R a^{1 / 3}
\end{aligned}
$$

$G r$ being the usual Grashof number, are well known. In the literature, casual use of equation (45) for $\mathrm{Pr} \geqslant 1$ 
fluids is somewhat surprising. Exceptions are the work of Churchill [16] and the correlation for vertical cavities suggested by Catton [17].

Attempts for correlating experimental data for $\operatorname{Pr} \geqslant 1$ fluids with equation (45) sometimes lead to an exponent less than $1 / 3$ for the Prandtl number. Also, there appears to be no agreement among experimentalists on the numerical value of this exponent. Equation (44) balanced with equation (45)

$$
N u \sim \Pi_{\mathrm{N}}^{1 / 3} \sim\left(\frac{P r}{1+P r}\right)^{1 / 3} R a^{1 / 3} \sim R a^{n},
$$

clearly shows that

$$
n=n(\operatorname{Pr})<1 / 3
$$

and cxplains the reason for disagreement among experimentalists on the numerical value of $n$.

A preliminary attempt by Arpaci and Kabiri [18] explains with $\Pi_{N}$ why some of the assumed (twentyseven!) transitions in the buoyancy-driven, turbulent flow between two horizontal plates do not actually exist (see Chu and Goldstein [19] and Garon and Goldstein [20]). A study on these 'transitions' with a two-layer heat transfer model including as well a core effect is under progress and will be reported later.

\section{CONCLUSIONS}

An attempt is made in this study to show the relation between the heat transfer correlations and the small (micro) scales of turbulence. A thermal microscale depending on the buoyant production of turbulent energy is proposed for any Prandtl fluid. The limits of this scale for $\operatorname{Pr} \rightarrow 1, \operatorname{Pr} \rightarrow 0$ and $\operatorname{Pr} \rightarrow \infty$ are shown to be the Kolmogorov, Oboukov-Corrsin and Batchelor scales, respectively. Expressing the proposed scale in terms of the buoyancy (force) rather than the buoyant production (of energy), an alternative form is given for this scale. The buoyant sublayer which controls the heat transfer is assumed to be characterized by this scale. A model resting on the proposed scale is then introduced for heat transfer in buoyancy-driven flows. The limits of the model for $\operatorname{Pr} \rightarrow 1, \operatorname{Pr} \rightarrow 0$ and $\operatorname{Pr} \rightarrow \infty$ turn out to be the wellknown heat transfer correlations. Also, the model appears to eliminate most of the assumed transitions in buoyancy-driven flow between horizontal plates.

The small scales of isotropic and anisotropic turbulence are found to be different. The small scales of homogeneous turbulence are expected to be identical, in the dimensional sense, to those of nonhomogeneous turbulence.

It is shown that a simple intuitive heat transfer model can be constructed without reference to an eddy diffusivity which does not have any fundamental base.

\section{REFERENCES}

1. G. I. Taylor, Statistical theory of turbulence, Proc. $R$. Soc. A151, 421 (1935).

2. A. N. Kolmogorov, Local structure of turbulence in incompressible viscous fluid for very large Reynolds numbers, C. r. Acad. Sci. USSR 30, 301 (1941).

3. A. M. Oboukhov, Structure of the temperature field in turbulent flows, Izv. Nauk. SSSR, Geogr. Geofiz. 13, 58 (1949).

4. S. Corrsin, On the spectrum of isotropic temperature fluctuations in isotropic turbulence, J. appl. Phys. 22, 469 (1951).

5. G. K. Batchelor, Small-scale variation of convected quantities like temperature in a turbulent fluid, J. Fluid Mech. 5, 113 (1959).

6. C. H. B. Priestley, Turbulent Transfer in the Lower Atmosphere. University of Chicago Press, Chicago, IL (1959).

7. A. A. Townsend, Structure of Turbulent Shear Flow. Cambridge University Press, Cambridge (1976).

8. W. K. George and S. P. Capp, Natural convection turbulent boundary layers next to heated vertical surfaces, Int. J. Heat Mass Transfer 22, 813 (1979).

9. M. A. Delichatsios, A new integral model for turbulent natural convection flows next to heated vertical walls, 5 th Symposium on Turbulent Shear Flows, Cornell University (1985).

10. H. B. Squire, In Modern Developments in Fluid Dynamics (Edited by $\mathrm{S}$. Goldstein). Oxford University Press, Oxford (1938).

11. E. Rukenstein, A correlation for laminar free convection over the entire range of Prandtl numbers, A.I.Ch.E. $J l$ 26, 850 (1960).

12. V.S. Arpaci and P. S. Larsen, Convection Heat Transfer. Prentice-Hall, Englewood Cliffs, NJ (1984).

13. H. Tennekes and J. L. Lumley, A First Course in Turbulence. MIT Press, Cambridge, MA (1972).

14. S. Corrsin, Turbulent dissipation fluctuations, Phys. Fluids 5, 1301 (1962).

15. H. Tennekes, Simple model for the small scale structure of turbulence, Phys. Fluids 11, 669 (1968).

16. S. W. Churchill, In Heat Exchanger Design Handbook (Edited by E. U. Schunder). Hemisphere, Washington, DC (1983)

17. 1. Catton, Natural convection in enclosures, Proc. 6 th Heat Transfer Conference, Toronto, Vol. 6, p. 13 (1978).

18. V. S. Arpaci and H. Kabiri, A theory for turbulent natural convection, 23rd National Heat Transfer Conference, Denver, CO (1985).

19. T. Y. Chu and R. J. Goldstein, Turbulent convection in a horizontal layer of water, J. Fluid Mech. 60, 141 (1973).

20. A. M. Garon and R. J. Goldstein, Velocity and heat transfer measurements in thermal convection, Phys. Fluids 16, 1818 (1973) 


\section{FORMULES DE MICRO-ECHELLES DE TURBULENCE ET DE} TRANSFERT THERMIOUE

Résumé-La petite échelle de structure des écoulements forcés turbulents développée après Taylor et Kolmogorov est étendue au cas des écoulements naturels libres. Une microéchelle thermique

$$
\eta_{\theta} \sim\left(\frac{1+\operatorname{Pr}}{\operatorname{Pr}}\right)^{1 / 4}\left(\frac{v a^{2}}{P_{\mathrm{B}}}\right)^{1 / 4}
$$

est proposée. Ici $P r=v / a$ représente le nombre de Prandtl et $P_{\mathrm{B}}$ la production d'énergie turbulente. Trois limites de cette échelle sont respectivement les échelles de Kolmogorov, d'Oboukhov-Corrsin et de Batchelor. Quand elle est exprimée en fonction de la force d'Archimède plutôt que de la production d'énergie, l'échelle proposée devient

$$
\eta_{\theta} \sim\left(\frac{1+P r}{P r}\right)^{1 / 3}\left(\frac{v a}{g \beta \Delta T}\right)^{1 / 3}
$$

Relativement à une échelle de longueur 1 caractéristique de la géométrie,

$$
\eta_{\theta} / 1 \sim \Pi_{\mathrm{N}}^{-1 / 3}
$$

où

$$
\Pi_{\mathrm{N}} \sim\left(\frac{\operatorname{Pr}}{1+\operatorname{Pr}}\right) R a
$$

est le nombre adimensionnel fondamental et $R a$ est le nombre de Rayleigh. Un modèle de transfert thermique basé sur ce nombre adimensionnel explique pourquoi la formule classique

$$
N u \sim R a^{\mathrm{n}}
$$

conduit à un exposant inférieur à $1 / 3$ quand on considère le mouvement entre deux plans horizontaux.

\section{TURBULENZKENNZAHLEN UND WÄRMEÜBERGANGSBEZIEHUNGEN}

Zusammenfassung-Die nach Taylor und Kolmogorow entwickelte Mikrostruktur erzwungener turbulenter Strömungen wird für freie Konvektionsströmungen erweitert. Eine thermische Kennzahl

$$
\eta_{\theta} \sim\left(\frac{1+P r}{P r}\right)^{1 / 4}\left(\frac{v a^{2}}{\mathscr{P}_{\mathrm{B}}}\right)^{1 / 4}
$$

wird vorgeschlagen. Darin bczcichnet $P r=v / a$ die Prandtl-Zahl und $\mathscr{P}_{\mathrm{B}}$ die Erzeugung an turbulenter Auftriebsenergie. Diese Kennzahl hat 3 Grenzfälle: die Kolmogorov-, die Oboukhov-Corrsin- und die Batchelor-Zahl. Formuliert man die Kennzahl mit Hilfe der Auftriebskraft---anstatt der Auftriebsenergieso ergiht sich

$$
\eta_{\theta} \sim\left(\frac{1+P r}{P r}\right)^{1 / 3}\left(\frac{v a}{g \beta \Delta T}\right)^{1 / 3}
$$

oder bezogen auf eine für die Geometrie charakteristische Länge 1

$$
\eta_{0} / l \sim \Pi_{\mathrm{N}}^{-1 / 3},
$$

wobei

$$
\Pi_{\mathrm{N}} \sim\left(\frac{P r}{1+P r}\right) R a
$$

die grundlegende dimensionslose Zahl der Auftriebsströmung und $R a$ die Rayleigh-Zahl ist. Ein Wärmeübergangsmodell, das auf dieser dimensionslosen Zahl basiert, erklärt, warum die bekannte Korrelation für freie Konvektion

$$
N u \sim R a^{n}
$$

bei Auftriebsströmungen zwischen 2 horizontalen Platten auf einen Exponenten kleiner als $1 / 3$ führt. 


\section{МИКРОМАСШТАБЫ ТУРБУЛЕНТНОСТИ И СООТНОШЕНИЯ ДЛЯ ТЕПЛОПЕРЕНОСА}

Аннотацяя-Теория мелкомасштабных вынужденных турбулентных течений, разработанная Тейлором и Колмогоровым, применяется к течениям, вызванным подъемной силой. Предложен тепјовой микромасштаб

$$
\eta_{\theta}-\left(\frac{1+P r}{P r}\right)^{1 / 4}\left(\frac{v a^{2}}{y_{\mathrm{B}}}\right)^{1 / 4}
$$

г де $\operatorname{Pr}=v / a$ число Прандтля, а $\mathscr{P}_{\mathrm{B}}$-генерирование подъемной турбуленгной энергии. Тремя пределами этого масштаба являются границы Колмогорова, Обухова-Корсина и Бэтчелора, соответственно. При выражении предложенного масштаба через подьемную силу, а не генерирование подъемной энергии, он имеет следующий вид

$$
\eta_{\theta}-\left(\frac{1+P r}{P r}\right)^{1 / 3}\left(\frac{1 \cdot a}{g \beta \Delta T}\right)^{1 / 3} .
$$

а соответсгвуюший масштаб длины $/$, характерный для геометрии, находится из соотношения:

$$
\eta_{\theta} / l \sim \Pi_{\mathrm{N}}^{-1 / 3}
$$

где

$$
\Pi_{\mathrm{N}} \sim\left(\frac{\operatorname{Pr}}{1+\operatorname{Pr}}\right) R a
$$

является фундаментальным безразмерным числом для течений. вызванных подъемной силой, а $R a$-число Рэлея. Модель теплопереноса, основанная на этом безразмерном числе, объясняет тот факт. почему хорошо известное выражение для естественной конвекции. $N u \sim R a^{n}$, приводит к показателю степени менее $1 / 3$, когда рассматривается случай течения между двумя горизонтальными пластинами. 